\title{
Mission (nearly) impossible: ERCP using an oblique cap with suction cannulation in a diffusely strictured duodenal stump after Billroth II with Braun enteroenterostomy
}

This is a unique clinical report of an 82year-old man with cholangitis post distal gastrectomy for treatment of ulcer disease $>35$ years ago, with no operative report available.

The patient was referred subacutely for ERCP, which could not be performed in the primary hospital owing to unclear anatomy. First using a forward-viewing colonoscope in the left-lateral position, a jejunal limb was readily reached via the lesser curvature, with a second lumen identifiable at the opposite side, suggesting Billroth II anatomy [1]. Further advancement of the scope revealed a putative Braun's enteroenterostomy; however, the expected third lumen was not readily identifiable. On further scrutiny, convoluted folds near the suture line came to our attention, and after mounting a cap, the apparently degenerated duodenal stump with a sharp angulation could be carefully entered with a visibly dilatory effect. The entire duodenal stump proved diffusely strictured, such that we switched to a cap-fitted gastroscope to limit perforation risks [2]. Cautious and patient push-and-pull movements with intermittent abdominal compression were needed to finally reach the papilla in a strictly tangential position ( Fig. 1, V Video 1). With a view to the ensuing utterly limited scope maneuverability and stability, we again exchanged for a double-lumen gastroscope with an oblique cap attached, with the shorter axis oriented to the papilla to better align into the putative biliary axis. Next, we applied a suction-assisted cannulation approach with a straight catheter, readily enabling deep biliary access, and multiple distal bile duct stones were confirmed (> Fig. 2 , \Video 1 ). The patient underwent endoscopic papillary balloon dilation up to $8 \mathrm{~mm}$ without endoscopic papillotomy, and partial stone extraction was performed using a wireguided basket [3]. Given an already high
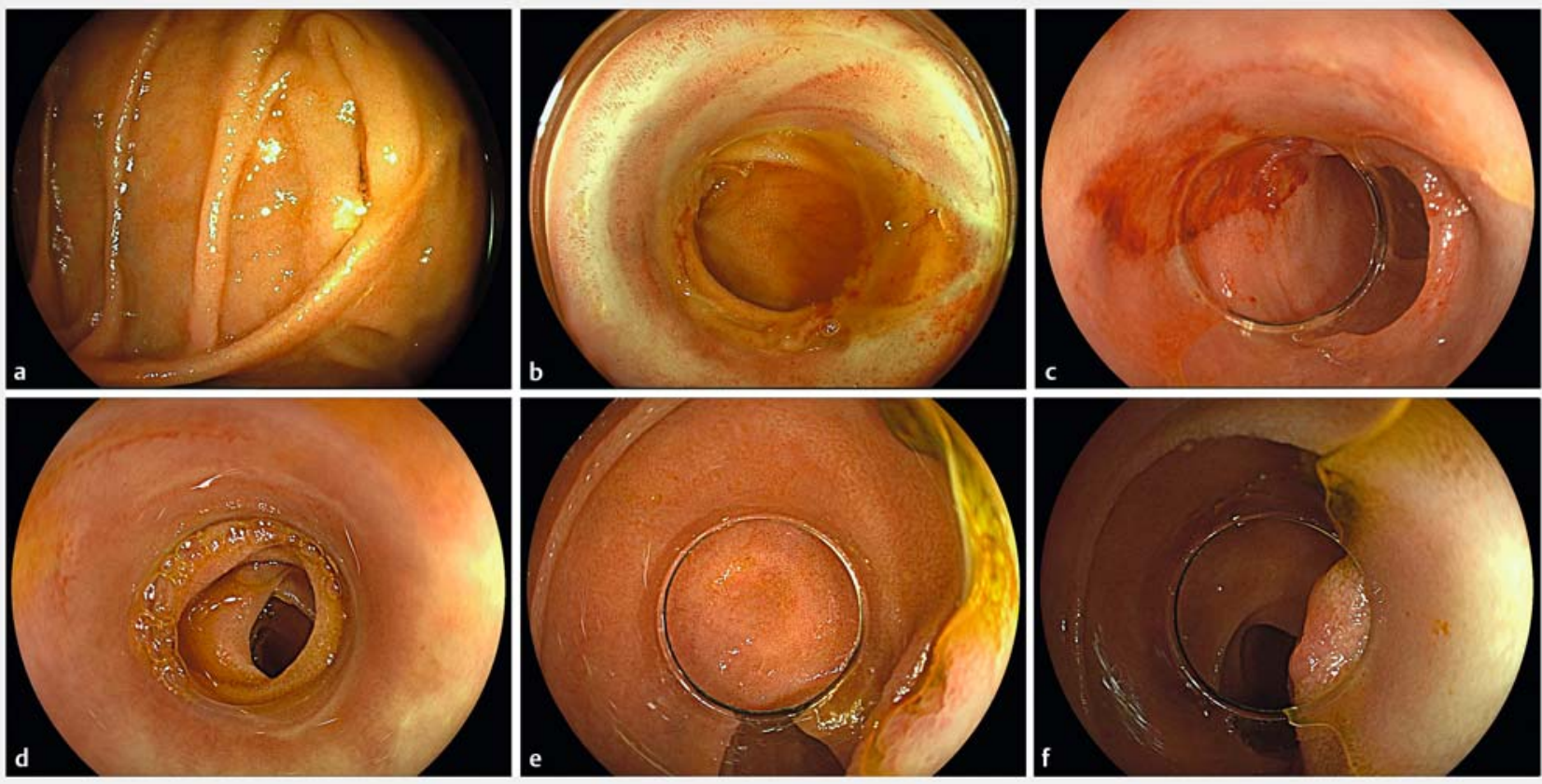

Fig. 1 Clarification of postsurgical anatomy and endoscopic access to the naïve papilla. a Explorative upper endoscopy using a forward-viewing colonoscope without a cap revealed a putative Braun enteroenterostomy, with the third lumen potentially degenerated and obscured at the 2 o'clock position. b Successful access into the duodenal stump after mounting a cap, which displaced the folds and was instrumental in transversing a sharp angulation, with marked tissue whitening reflective of de facto dilation. $\mathbf{c}$ Given the high perforation risks associated with continued use of the colonoscope passing through the diffusely strictured duodenal stump, we switched to a cap-fitted standard gastroscope, which revealed mucosal tears but no transmural defects. $\mathbf{d}$ Further illustration of normal duodenal mucosa and lumen-narrowing circular folds. e, $\mathbf{f}$ The naïve papilla reached at a tangential 3-4 o'clock position with suboptimal operability in terms of cannulation and duct access. In consideration of primary endoscopic access to the jejunum via the lesser curvature, with the duodenal stump entrance at the opposite side of the suture line, a final assumption of postoperative situs as "antiperistaltic Billroth II" with Braun procedure was made. 

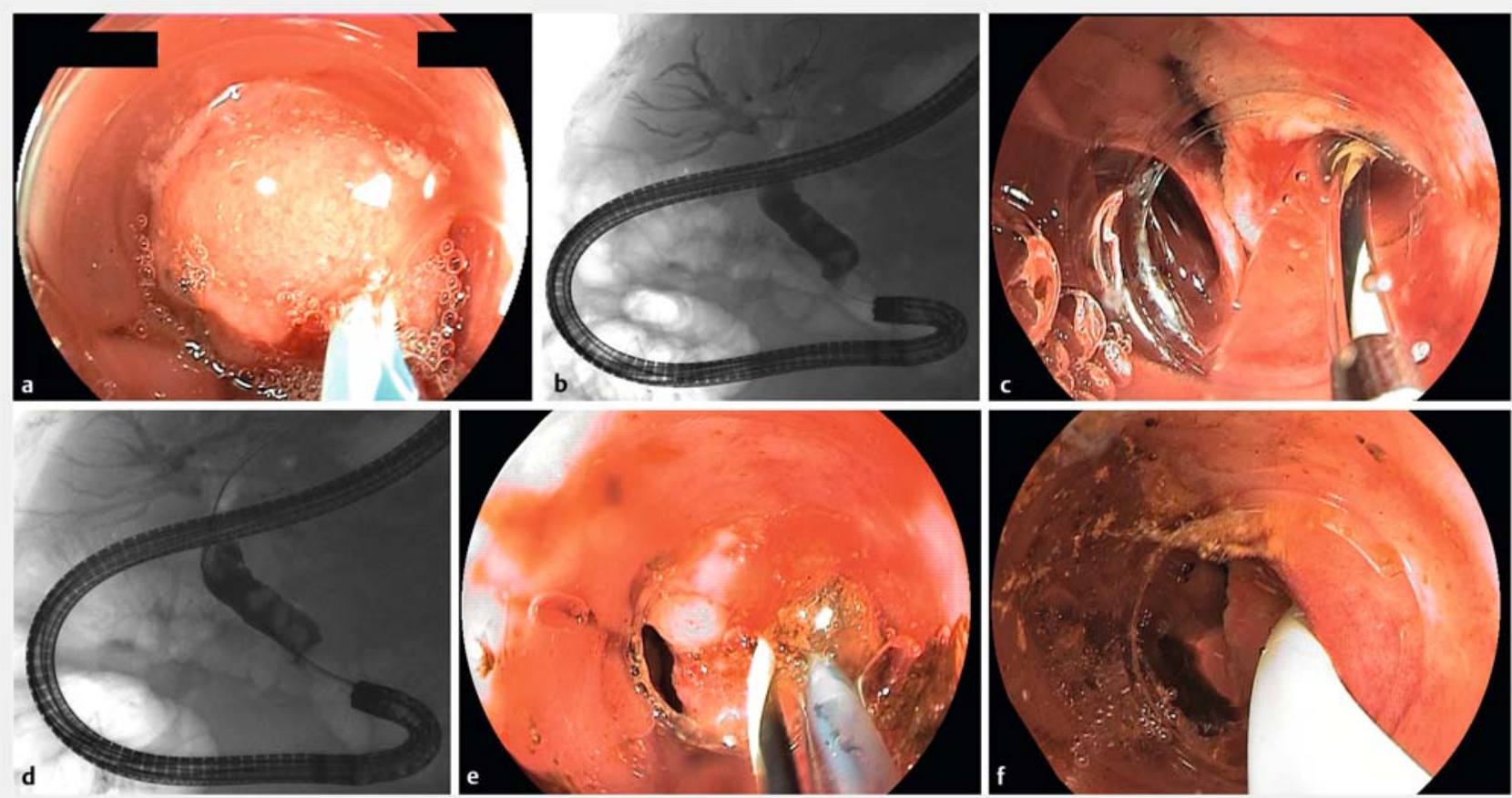

- Fig. 2 Biliary access using suction-assisted cannulation by an oblique cap-fitted double-lumen gastroscope and biliary interventions. a Successful bile duct access by a guidewire-loaded straight cannula after aspiration of the papilla into the oblique cap, with the short axis oriented to the papilla. $\mathbf{b}$ Cholangiogram confirmed high distal stone load in a dilated common bile duct. $\mathbf{c}$ Endoscopic large-balloon dilation up to 8 mm was performed. d, e Partial stone extraction was performed using a wire-guided Dormia basket. $\mathbf{f}$ Given the high consumption of analgosedation, complete stone extraction was postponed, and a temporary biliary double-pigtail plastic stent was inserted.

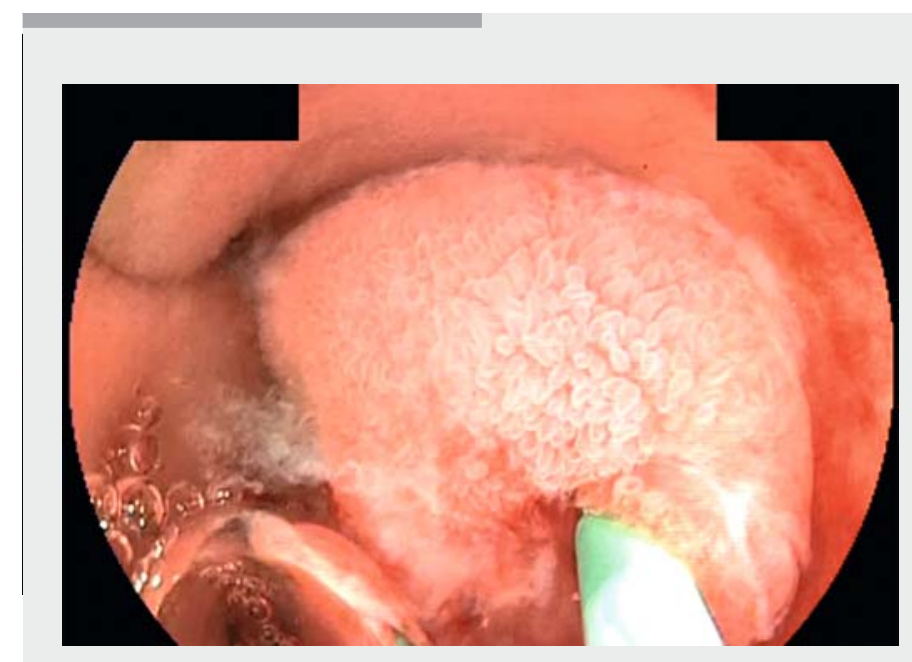

$\checkmark$ Video 1 Access to the papilla and successful biliary intervention in a degenerated duodenal stump with diffuse stricturing after Billroth II with Braun enteroenterostomy.

demand on analgosedation, we opted for temporary bile duct stenting, inserting a 10-Fr double-pigtail stent and postponing complete stone clearance for another ERCP session.
Endoscopy_UCTN_Code_TTT_1AR_2AG

\section{Competing interests}

None
The author

\section{Vincent Zimmer ${ }^{1,2}$}

1 Marienhausklinik St. Josef Kohlhof, Department of Medicine, Neunkirchen, Germany

2 Department of Medicine II, Saarland University Medical Center, Homburg, Germany

Corresponding author

\section{Vincent Zimmer, MD}

Department of Medicine, Marienhausklinik St. Josef Kohlhof, Klinikweg 1-5, 66539 Neunkirchen, Germany Fax: +49-6821-3632624 vincent.zimmer@gmx.de

\section{References}

[1] Park TY, Bang CS, Choi SH et al. Forwardviewing endoscope for ERCP in patients with Billroth II gastrectomy: a systematic review and meta-analysis. Surg Endosc 2018; 32: $4598-4613$ 
[2] Bove $V$, Tringali A, Familiari P et al. ERCP in patients with prior Billroth II gastrectomy: report of 30 years' experience. Endoscopy 2015; 47: 611-616

[3] Jang HW, Lee KJ, Jung MJ et al. Endoscopic papillary large balloon dilatation alone is safe and effective for the treatment of difficult choledocholithiasis in cases of Billroth II gastrectomy: a single center experience. Dig Dis Sci 2013; 58: $1737-1743$

\section{Bibliography}

DOI https://doi.org/10.1055/a-0999-5090

Published online: 17.9.2019

Endoscopy 2020; 52: E63-E65

(c) Georg Thieme Verlag KG

Stuttgart · New York

ISSN 0013-726X

\section{ENDOSCOPY E-VIDEOS}

https:/|eref.thieme.de/e-videos

回局 Endoscopy E-Videos is a free access online section, reporting 回和: on interesting cases and new

techniques in gastroenterological endoscopy. All papers include a high quality video and all contributions are freely accessible online.

This section has its own submission website at

https://mc.manuscriptcentral.com/e-videos 